\title{
Correction to: Changes in the sugars, amino acids and organic acids of postharvest sperminetreated immature vegetable soybean (Glycine max L. Merr.) as determined by ${ }^{1} \mathrm{H}$ NMR spectroscopy
}

Jiangfeng Song ${ }^{1 *}$, Gang $\mathrm{Wu}^{2}$, Tao Li ${ }^{3}$, Chunquan $\mathrm{Liu}^{1}$ and Dajing $\mathrm{Li}^{1 *}$

Correction: Food Production, Processing and Nutrition 2, 7 (2020)

https://doi.org/10.1186/s43014-020-00021-1

Following publication of the original article (Song et al. 2020), the authors realised the Fig. 1 was not very clear. The clear figure is given below.

\section{Author details}

IInstitute of Farm Product Processing, Jiangsu Academy of Agricultural Sciences, Nanjing 210014, P.R. China. ${ }^{2}$ Jiangsu Gian Food Co., Ltd., Nantong 226363, P.R. China. ${ }^{3}$ Dongtai Lvjiayuan Food Co. Ltd., Yancheng 224005, P.R. China.

Published online: 31 July 2020

\section{Reference}

Song, et al. (2020). Changes in the sugars, amino acids and organic acids of postharvest sperminetreated immature vegetable soybean (Glycine max L. Merr.) as determined by ${ }^{1} \mathrm{H}$ NMR spectroscopy. Food Production, Processing and Nutrition, 2, 7. https://doi.org/10.1186/s43014-020-00021-1.

The original article can be found online at https://doi.org/10.1186/s43014020-00021-1.

*Correspondence: songjiangfeng102@163.com; lidajing@163.com

1 Institute of Farm Product Processing, Jiangsu Academy of Agricultural

Sciences, Nanjing 210014, P.R. China

Full list of author information is available at the end of the article

(c) The Author(s). 2020 Open Access This article is licensed under a Creative Commons Attribution 4.0 International License, which permits use, sharing, adaptation, distribution and reproduction in any medium or format, as long as you give appropriate credit to the original author(s) and the source, provide a link to the Creative Commons licence, and indicate if changes were made. The images or other third party material in this article are included in the article's Creative Commons licence, unless indicated otherwise in a credit line to the material. If material is not included in the article's Creative Commons licence and your intended use is not permitted by statutory regulation or exceeds the permitted use, you will need to obtain permission directly from the copyright holder. To view a copy of this licence, visit http://creativecommons.org/licenses/by/4.0/. 

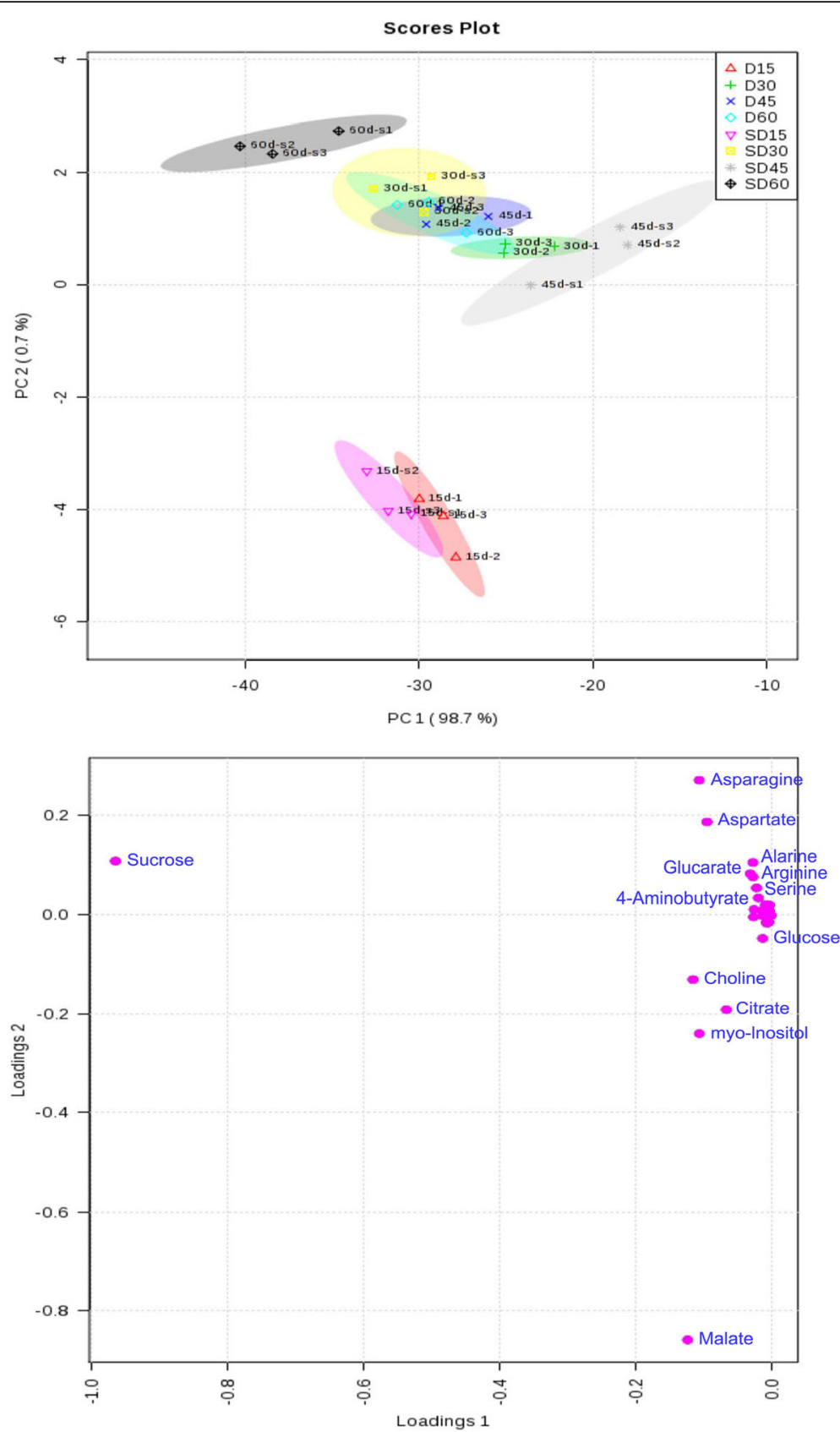

Fig. 1 Score and loading plots of effect of exogenous spermine on metabolite profiles of cold-stored immature vegetable soybeans 